\title{
The Effects of Dynamic Warm Up with and without Ball on Passing Performance and Drippling in Soccer
}

\author{
Nurten Dinç \\ Correspondence: Nurten Dinç, Manisa Celal Bayar University, Faculty of Sports Sciences, Turkey. \\ Received: December 25, 2018 \\ Accepted: January 27, 2019 Online Published: January 29, 2019 \\ doi:10.11114/jets.v7i3.3906 \\ URL: https://doi.org/10.11114/jets.v7i3.3906
}

\begin{abstract}
Introduction and Aim: The purpose of this study is to investigate the effect of mass warm-up specific to sports branch and dynamic warm-up on pass performance and dribbling in soccer.

Method: The study was conducted on soccer team competing in amateur league. A total of 10 volunteers without any health problems and disabilities participated in the study. The participants performed two different warm-up protocols; namely dynamic warming and branch specific warming. Participants performed two warm-up protocols in 15 minutes. Following the warm-up protocols, the participants applied pass test and drippling. Intergroup analysis Wilcoxon signed rank test was applied in order to observe the effects of dynamic warm-up and branch specific warm-up of the participants on pass test and ball dribbling.

Findings and Conclusion: Comparing the effects of branch-specific warm-up and dynamic warm-up on pass test, it has been observed that there is a positively and statistically significant difference in branch-specific warm-up compared to dynamic warm-up $(\mathrm{p}<0.05)$. No statistically significant difference has been observed on ball dribbling performance when comparing the warm-up protocols ( $\mathrm{p}>0.05)$.
\end{abstract}

Keywords: soccer, warm-up, pass test, drippling

\section{Introduction}

Soccer (football) contains high intensity intermittent movements including sprint, jump, sudden speed changes (Pagaduan et al., 2012) and requires correct warm-up technique for a good match performance (Eniseler, 2010). The general purpose of warm-up is to increase the tissue temperature before physical activity (Hendrick et al., 1992). Possible effects of warm-up related to temperature are as follows; it accelerates metabolic reactions, increases the rate of nerve conduction, increases the release of oxygen from hemoglobin and myoglobin, reduces friction in muscles and joints, non-temperature-related effects of warm-up are increase in the blood flow to the muscles, increase in the basic oxygen consumption and resulting post-activation potentiation following the increased neuromuscular activation (Bishop 2003). In addition, warm-up has positive effects on reducing muscle injuries (Woods et al., 2007).

Warm-up techniques can generally be classified into two main categories as passive warm-up and active warm-up. Passive warm-up includes raising the muscle temperature or core temperature via some external ways. Active warm-up requires exercise and can lead to greater metabolic and cardiovascular changes than passive warm-up. Typical examples of active warm-up include jogging, calisthenics, cycling and swimming (Bishop 2003). When the literature is examined, various warm-up routines are investigated to improve performance (Dinc \& Hayta, 2018; Gelen et al., 2008; Samson et al., 2012; Zois et al., 2011). Recent studies have shown that static and dynamic stretching have different effects on athletic performance (Faigenbaum et al., 2005; McNeal \& Sands., 2003). In the literature, it has been revealed that static stretching exercises negatively affect the performance (Bradley et al., 2007; Gelen et al., 2008; Taylor et al., 2009) and decrease the power capacity during the force tests (Ergin and Bereket Yücel, 2011; Little and Williams, 2006; Fletcher and Jones, 2004). Knowing the negative effects of static stretching before athletic performance has led to search for alternative methods by scientists working in the field of sports, coaches and athletes (Cilli et al., 2014). Dynamic stretching which requires controlled movement along the active range of motion for each joint (Fletcher 2010) is currently replacing static stretching in modern athletic warm-up (Behm \& Chaouachi, 2011). Studies have reported that dynamic warm-up positively affects performance (Holt \& Lambourne, 2008; Faigenbaum et.al.,2006; Amiri-Khorasani \& Gulick, 2015; Ahmadabadi et al.,2015). But warm-up should be dense enough to increase the body's core temperature, but it should not be too dense to tire athlete (Devore, 2006). If warm-up is too severe and long to cause fatigue, it will 
cause excessive rise in body temperature and depletion of glycogen stores which will impair medium and long-term performance (Eniseler, 2010). Although the current studies generally focus on static and dynamic exercises, the literature does not include warm-up with balls. In soccer branch, warm-up should include directional, non-directional, side-to-back, speed-changing races, sprint and such soccer-specific exercises as agility and jump. With the exercises performed with the ball, the player must be prepared for the game (Eniseler, 2010). Therefore, the purpose of this study is to investigate the effect of mass warm-up specific to sports branch and dynamic warm-up on pass performance and ball dribbling.

\section{Method}

The study was conducted on Seferihisar Municipality soccer team competing in amateur league. A total of 10 volunteers without any health problems and disabilities participated in the study. Medical reports of participants were requested before participating in the test.

\subsection{Test Protocol}

The study was conducted during the preparation phase of soccer team. The participants performed two different warm-up protocols, namely dynamic warming and branch specific warming (table 1). Participants performed the warm-up protocols on different days. As dynamic warm-up, they performed a five-minute jogging between 150-160 heartbeats followed by the routines involving joint mobility without any extra weight. In branch specific warm-up, warm-up was performed with dribbling in different directions with the running pace between 150-160 heartbeats and pass exercises in various distances and types. Participants performed two warm-up protocols in 15 minutes. Following the warm-up protocols, the participants applied Lougborough pass test of which Ali et al. (2007) performed validity and reliability studies and then ball dribbling test. Durations of pass test and ball dribbling were measured with a timer and evaluated as a test score.

Table 1. Warm-up protocol

\begin{tabular}{|c|c|c|}
\hline \multirow{14}{*}{ Warm-up } & \multirow{7}{*}{ Dynamic warm-up } & 5 min. jogging \\
\hline & & Internal and extarnal rotation \\
\hline & & Back and forth slipping step \\
\hline & & Knee pull up exercise \\
\hline & & Side running \\
\hline & & Speed running \\
\hline & & Back and forth $\mathrm{S}$ running \\
\hline & \multirow{7}{*}{ Branch specific warm-up } & Hot ball stutter (Head, inside-outsise -instep surfaces) \\
\hline & & Pass within five metres \\
\hline & & Left/right control pass within five metres \\
\hline & & Paired dynamic inside of the foot pass within 1.5 metres \\
\hline & & Paired dynamic instep of the foot pass within 1.5 metres \\
\hline & & Paired dynamic head pass within 1.5 metres \\
\hline & & Long pass (20-25 m) \\
\hline
\end{tabular}

\subsection{Pass Test}

Four pieces of gymnastic board are placed as shown. 2 boards are placed in 12 meters and the other two boards are placed as 9.5 meters and in rectangular shape. Before this placement, 4 cards in different colors (green, blue, red and white) $(0.6 \times 0.3 \mathrm{~m})$ are placed right in the middle of all boards. Also, the target plates are placed in the center of these colored cards horizontally. The pass test is shown in figure 1. 


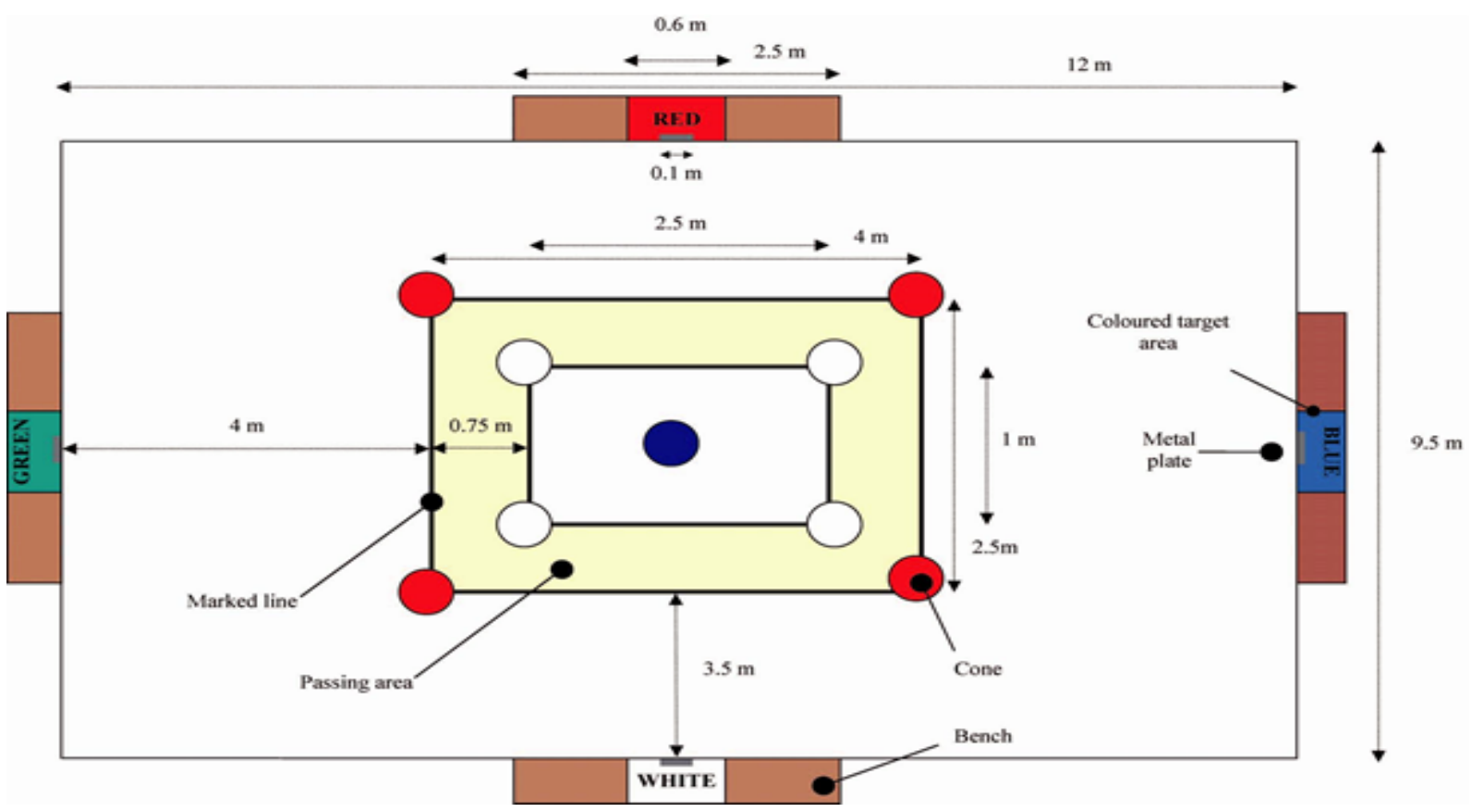

Figure 1. Loughborough Soccer Passing Test (Ali et al, 2007)

Rules and penalties to be applied in pass test.

Two soccer coaches participated as assistant in application of pass test. The participant will start from the center together with the ball and the first assistant coach keep the time. The test starts after the participant touches the ball and the ball leaves the first rectangle. The $2^{\text {nd }}$ assistant coach tells the participant in what color s/he will hit the target. Next target is always notified immediately before the pass. The targets are randomly notified by the $2^{\text {nd }}$ assistant coach. Each test is composed of a total of 8 long (green and blue) and 8 short (white and red) pass. Each pass must be made within the pass area for evaluation. The ball must definitely be within 2 rectangles when starting the pass in compensation of previous pass. In addition, the participants are informed about the fact that the test must be completed as soon as possible and with minimal error to ensure that the test is completed successfully. The second assistant coach ends the time when the last pass strikes the target on the board. No information or feedback is provided about the test results. The $2^{\text {nd }}$ assistant coach also records the penalty time, so the $2^{\text {nd }}$ assistant coach must be in an area where all targets are visible. Time penalties are indicated as follows:

- 5 secs are deducted when the target is completely missed or the pass is directed to the wrong target

- 3 secs are deducted when the target is missed $(0.6 \times 0.3) \mathrm{m}$

- 3 secs are deducted when the ball is touched with the hand

- 2 secs are deducted when the pass is made out of the pass area

- 2 secs are deducted if the ball touches any cone

- $1 \mathrm{sec}$ is deducted for each second passing after 43 secs

- $1 \mathrm{sec}$ is deducted if pass hits the $10 \mathrm{~cm}$ exact center (Ali et al., 2007).

\subsubsection{Ball Dribbling}

In the test area (McGregor et al., 1999) established by placing 6 cones with 3 meter interval, the participants start from the starting line and dribbles the ball between the cones and exit the finish line. If a cone falls during the test, the test is suspended and the participant starts the test again by coming back to starting point. Participants' time from start to finish is recorded as a test score.

\subsection{Data Analysis}

SPSS 22 package program was used for the statistical analyses of the study. Intergroup analysis Wilcoxon signed rank test was applied in order to observe the effects of dynamic warm-up and branch specific warm-up of the participants on pass test and ball dribbling. The significance level used during the study is 0.05 . 


\section{Results}

Age, height, weight and body mass index (BMI) information of the participants are given in Table 2.

Table 2. Demographic information of the participants

\begin{tabular}{|c|c|}
\hline & Ort \& S.S \\
\hline Age & $20.8 \pm 4.3$ \\
\hline Height & $180 \pm 8.06$ \\
\hline Weight & $80.2 \pm 14.04$ \\
\hline BMI & $24.59 \pm 2.07$ \\
\hline
\end{tabular}

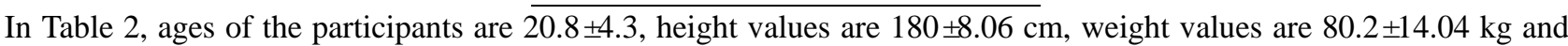
body mass index values are indicated as $24.59 \pm 2.07$.

The results of pass test and ball dribbling test obtained following the dynamic and branch-specific warm-up protocols of the participants are given in Table 3. The difference between warm-up protocols was analyzed with Wilcoxon ranks test.

Table 3. Difference between the warm-up protocols of the participants with and without ball

\begin{tabular}{llll}
\hline Pass Test & Ort \& S.S & $\mathrm{Z}$ & $\mathrm{p}$ \\
\hline DW & $0.91 \pm 0.34$ & -2.295 & $0.22^{* *}$ \\
BW & $0.68 \pm 0.26$ & & \\
\hline Dribbling & Ort \& S.S & $\mathrm{Z}$ & $\mathrm{p}$ \\
\hline DW & $10.74 \pm 1.29$ & -1.172 & 0.241 \\
BW & $10.27 \pm 0.78$ & & \\
\hline
\end{tabular}

DW: dynamic warm-up - BW: branch-specific warm-up p $<0.05^{* *}$

Comparing the effects of branch-specific warm-up and dynamic warm-up on pass test by the analysis results of Wilcoxon Rank, it has been observed that there is a positively and statistically significant difference in branch-specific warm-up compared to dynamic warm-up $\mathrm{p}<0.05$. No statistically significant difference has been observed on ball dribbling performance when comparing the warm-up protocols $\mathrm{p}>0.05$.

\section{Discussion}

Warm-up minimizes the risk of injury and it must increase body and muscle temperature, activate muscle groups, stimulates nervous system, accelerate metabolic reactions and increase joint mobility in order to prepare the player for an optimal performance (Devore, 2016). Looking at the literature, the studies generally focus on passive and active warm-up and have revealed the acute disruptive effect of static stretching on explosive exercise performance. One possible mechanism that may explain the power output deficit of static stretching is the reduction in muscle stiffness (Kubo et al. 2011). For this reason, dynamic stretching is recommended in warm-up rather than static stretching. As different from other studies, this study analyzes the effect of dynamic warm-up and branch-specific warm-up with the ball in soccer players on pass performance and ball dribbling. According to the results of the study, it has been determined that the branch-specific warm-up has statistically positive effect on the pass test compared to dynamic warm-up and no statistically significant difference is observed in the ball dribbling test.

Increased muscle temperature after active warm-up increases blood flow to working muscles and makes aerobic contribution to energy metabolism at the beginning of exercise (Gray \& Nimmo, 2001) and positively affects power performance. Dynamic flexibility exercises can also be simulated with the movements of soccer. So, this facilitates the transfer of dynamic flexibility development to the soccer game. Looking at the studies performed on soccer branch, Pandguan et al. (2012) have determined that the best result in countermovement jump performance following 6 different warm-up methods emerges in dynamic stretching performed together with the general warm-up.

Passive warm-up reduces the negative effect of static stretching in jump performance when combined with general warm-up and dynamic stretching. Faigenbaum et al. (2005) have investigated the effect of different warm-up protocols on anaerobic performance and determined that dynamic warm-up and static warm-up combined with dynamic warm-up have positive effect on speed, health ball and vertical jump. Gelen et al. (2010) have established that static stretching and dynamic exercises following a 5-minute jogging have neither positive nor negative impact on sprint, slalom dribbling and penalty kick performance and the known harmful effects of static stress can be partially reduced with the combination of static stretching and dynamic exercises after a 5-minute jogging. Little et al. (2006) have stated that 
static stretching doesn't affect high-speed performance negatively when it is included in warm-up of professional soccer players and dynamic stretching during warm-up is the most effective method as the preparation for the high-speed performance. The reason for the decrease in the performance caused by static stress has been associated with the long duration of stretching.

Warm-up must be dense enough to sufficiently increase the body's core temperature, not too much to cause fatigue of athletes (Devore, 2006). Warm-up before the match in soccer lasts 30-45 minutes. The muscle temperature rises rapidly in 3-5 minutes with warm-up. It reaches the plateau within 10-20 minutes. The duration of warm-up changes by the intensity of warm-up. While Warm-up duration over 10 minutes within the exercise intensity of $60-80 \%$ of $\mathrm{Max}_{\mathrm{VO}_{2}}$ is reported to increase long-term exercise efficiency, 23 min team-sport warm-up caused exhaustion by increasing muscle temperature. Prolonged warm-up routines lead to decreased performance by increasing fatigue, consuming muscle glycogen stores and raising core temperature early (Zois et al. 2011). Besides, when associated with the decrease in muscle viscosity extended WU time can cause an increase in the muscle temperature, neuro transmittal speed and muscle enzymatic cycle (Bishop, 2003). Thus, warm-up for soccer should neither be long nor short. The balance between warm-up and fatigue must be established well. Apart from this, the warm-up duration also changes by the air temperature and purpose. As the air temperature rises, the duration of warm-up should be reduced (Eniseler, 2010).

Nowadays pap has been applied plus warm-up protocols. According Nededham et.al. (2009) noted that when compared to static or dynamic war-up protocols resistance exercise performed for 3 to 6 minutes just after dynamic exercise increased cip. Zois et. al. found that a leg-press warm-up may improve acute team-sport performance tests when compared to a traditional warm-up protocol. In their study Zois et.al. (2011) differentiated in general warm-up protocols by using small-sided game. Approximately a 12 minutes small-sided games was found to increase the jumping performance up to $6 \%$ and reactive agility $4 \%$. The results showed meaningful differences in the pass tests applied after the 15 minutes period of collective warm-up defined in this study when compared to the ones performed without a ball. Synchronized muscle movement is also important for managing ball control, to release the required energy to gain a specific speed and altitude within the short and long passes during the collective warm-up apart from the positive effect of muscle contraction which increases muscle temperature more than dynamic warm-up. Within this context, positive effect on performance is evident.

\section{References}

Ahmadabadi, F., Avandi, S. M., \& Aminian-Far, A. (2015). Acute versus Chronic dynamic warm-up on balance and balance the vault performance in skilled gymnast. International Journal of Applied Exercise Physiology, 4(2), 20-33.

Ali, A., Williams, C., Hulse, M., Strudwick, A., Reddin, J., Howarth, L., ... McGregor, S. (2007). Reliability and validity of two tests of soccer skill. Journal of Sports Science, 25, 1461-1470. https://doi.org/10.1080/02640410601150470

Amiri-Khorasani, M., \& Gulick, D. T. (2015). Acute effects of different stretching methods on static and dynamic balance in female football players. International Journal of Therapy and Rehabilitation, 22(2), 68-73. https://doi.org/10.12968/ijtr.2015.22.2.68

Behm, D. G., \& Chaouachi, A. (2011). A review of the acute effects of static and dynamic stretching on performance. European journal of applied physiology, 111(11), 2633-2651. https://doi.org/10.1007/s00421-011-1879-2

Bishop D. (2003). Warm up I, Potential mechanisms and the effects of passive warm up on exercise performance. Sports Medicine, 33(6), 439-454. https://doi.org/10.2165/00007256-200333060-00005

Bradley, P. S., Olsen, P. D., Porta, M. D. (2007). The effect of static, ballistic, and proprioceptive neuromuscular facilitation stretching on vertical jump performance. Journal of Strength and Conditioning Research, 21(1), 223226. https://doi.org/10.1519/00124278-200702000-00040

Cilli, M., Gelen, E., Yildiz, S., Saglam, T., \& Camur, M. H. (2014). Acute effects of a resisted dynamic warm-up protocol on jumping performance. Biolgy Sport, 31, 277-282. https://doi.org/10.5604/20831862.1120935

Devore P. (2006). A pregame soccer warm-up. National Strength and Conditioning Association, 28(1), 14-18. https://doi.org/10.1519/00126548-200602000-00002

Dinç, N., \& Hayta, Ü. (2018). Effect of Bulgarian Split Squat Exercise on 20 Meters Sprint Performance. Journal of Education and Training Studies, 6(9), 141-145. https://doi.org/10.11114/jets.v6i9.3391

Eniseler, N. (2010). Bilimin ışı̆̆ında futbol antrenmanı. Birleşik Matbaacılık, Manisa 54-58.

Ergin, E., \& Bereket, Y. S. (2011). Farklı germe egzersizlerinin üst ve alt ektremite kuvvet parametrelerine akut etkileri. Spor Hekimliği Dergisi, 46, 145-153. 
Faigenbaum, A. D., Bellucci, M., Bernieri, A., Bakker, B., \& Hoorens, K. (2005). Acute effects of different warm-up protocols on fitness performance in children. The Journal of Strength \& Conditioning Research, 19(2), 376-381.

Fletcher, I. M., \& Jones, B. (2004). The effect of different warm-up stretch protocols on 20 meter sprint performance in trained rugby union players. The Journal of Strength \& Conditioning Research, 18(4),885-888.

Gelen, E. (2010). Acute effects of different warm-up methods on sprint, slalom dribbling, and penalty kick performance in soccer players. Journal of Strength and Conditioning Research, 24(4), 950-956. https://doi.org/10.1519/JSC.0b013e3181cb703f

Gelen, E., Saygın, Ö., Karacabey, K., \& Kılınç, F. (2008). Acute effects of static stretching on vertical jump performance in children. Journal of Human Sciences, 5(1), 1-10.

Gray, S., \& Nimmo, M. (2001). Effects of active, passive or no warm-up on metabolism and performance during high-intensity exercise. Journal of Sports Sciences, 19, 693-700. https://doi.org/10.1080/02640410152475829

Hedrick, A. (1992). Physiological responses to warm-up. Journal of Strength and Conditioning Research, 14, 25-27. https://doi.org/10.1519/0744-0049(1992)014<0025:PRTWU>2.3.CO;2

Holt, B. W., \& Lambourne, K. (2008). The impact of different warm-up protocols on vertical jump performance in male collegiate athletes. The Journal of Strength \& Conditioning Research, 22(1), 226-229. https://doi.org/10.1519/JSC.0b013e31815f9d6a

Kubo, K., Kanehisa, H., \& Fukunaga, T. (2001). Is passive stiffness in human muscles related to the elasticity of tendon structures? European Journal of Applied Physiology, 85(3-4), 226-232. https://doi.org/10.1007/s004210100463

Little, T., \& Williams, A. G. (2006). Effect of differential stretching protocols during warm-up on high-speed motor capacities in Professional soccer players. The Journal of Strength \& Conditioning Research, 20(1), 203-207.

McGregor, S. J., Nicholas, C. W., Lakomy, H. K. A., \& Williams, C. (1999). The influence of intermittent high-intensity shuttle running and fluid ingestion on the performance of a soccer skill. Journal of Sports Sciences, 17(11), 895-903. https://doi.org/10.1080/026404199365452

McNeal, J. R., \& Sands, W. A. (2003). Acute static stretching reduces lower extremity power in trained children. Pediatric Exercise Science, 15(2), 139-145. https://doi.org/10.1123/pes.15.2.139

Needham, R. A., Morse, C. I., \& Degens, H. (2009) The acute effect of different warm-up protocols on anaerobic performance in elite youth soccer players. The Journal of Strength \& Conditioning Research, 23(9), 2614-2620. https://doi.org/10.1519/JSC.0b013e3181b1f3ef

Pagaduan, J. C., Pojskić, H., Užičanin, E., \& Babajić, F. (2012). Effect of various warm-up protocols on jump performance in college football players. Journal of human kinetics, 35(1), 127-132.

https://doi.org/10.2478/v10078-012-0086-5

Samson, M., Button, D. C., Chaouachi, A., \& Behm, D. G. (2012). Effects of dynamic and static stretching within general and activity specific warm-up protocols. Journal of Sports Science and Medicine, 11, 279-285.

Taylor, K. L., Sheppard, J. M., Lee, H., \& Plummer, N. (2009). Negative effect of static streching restored when combined with a sport specific warm-up component. Journal of Science and Medicine in Sport, 12, 657-661. https://doi.org/10.1016/j.jsams.2008.04.004

Woods, K., Bishop, P., \& Jones, E. (2007). Warm-up and stretching in the prevention of muscular injury. Sports Medicine, 37(12), 1089-1099. https://doi.org/10.2165/00007256-200737120-00006

Zois, J., David, J., Bishop, D. J., Ball, K., \& Aughey, R. J. (2011). High-intensity warm-ups elicit superior performance to a current soccer warm-up routine. Journal of Science and Medicine in Sport. 14(6), 522-528.

https://doi.org/10.1016/j.jsams.2011.03.012

\section{Copyrights}

Copyright for this article is retained by the author(s), with first publication rights granted to the journal.

This is an open-access article distributed under the terms and conditions of the Creative Commons Attribution license which permits unrestricted use, distribution, and reproduction in any medium, provided the original work is properly cited. 